\title{
Mathematics Education as a Mathematician's Research Area: An Invitation for Collaboration
}

\author{
Cynthia O. Anhalt and Ricardo Cortez
}

The current
climate around
mathematics
education
research is
collaborative.

Mathematicians have made significant contributions to mathematics education, especially at the college level. It is natural for mathematicians in academia to develop effective ways of teaching mathematics. The projects that tend to have more impact are those informed by current research based on established theoretical frameworks. Here, we make a case for more mathematicians to get involved in K-16 education research in collaboration with mathematics educators. While there have been many calls for mathematicians to get involved in mathematics education, especially in teacher preparation, ${ }^{1}$ our interest is in promoting collaborative research. Mathematics education is a distinct discipline that mathematicians can study systematically in the same way mathematics is used to understand current research questions in the physical and social sciences. This involves becoming familiar with the body of work that has led to

Ricardo Cortez is the Pendergraft William Larkin Duren Professor of mathematics at Tulane University. His email address is rcortez@tulane.edu.

Cynthia Oropesa Anhalt is associate research professor and director of the Secondary Mathematics Education Program at the University of Arizona. Her email address is canha1t@math . arizona. edu.

${ }^{1}$ See, for example, the CBMS MET II Report (https://bit $.7 \mathrm{y} / 2 \mathrm{q} 7 \mathrm{ZMee}$ ) and the Notices special issue (https://bit.1y /2Iu1Zd2).

For permission to reprint this article, please contact: reprint-permission@ams .org.

DOI: http://dx.doi.org/10.1090/noti1722 the current questions. Hyman Bass (2005) argued that "the first task of the mathematician who wishes to contribute [to mathematics education] is to understand sensitively the domain of application, the nature of its mathematical problems, and the forms of mathematical knowledge that are useful and usable in this domain" (p. 418). The current climate around mathematics education research is collaborative and inviting of synergistic partnerships. We hope to motivate research mathematicians to establish collaboration with mathematics education researchers. We also describe some issues of current importance where such collaborations are needed.

\section{Benefits to be Gained from Collaborations}

The field of mathematics education is both a research discipline and an area of practical application. From a practical point of view, teaching at any level, from preschool to graduate, involves teacher/instructor flexibility in knowledge of age-appropriate pedagogy and varying content matter. Learning mathematics can differ significantly at the various levels due to the nature of human cognitive development, learning environments, and social contexts. It is within these settings that the research in mathematics education takes place. Research topics may include a focus on how students make sense of certain content or the dynamics of group work.

Social aspects include tensions between agents of change and those who resist it and issues of inclusion, equity, and access. The need for inclusion of traditionally underserved students invites further research. Mathematics education would benefit from collaborative research between mathematics educators and mathematicians.

\section{Developing a Collaboration}

The authors of this article collaborate on research projects related to mathematical modeling in K-12 education. This collaboration started through a series of collegial 
discussions at the 2012 annual conference of the Society for Advancement of Chicanos/Hispanics and Native Americans in Science (SACNAS) during a session on the added demands on the $\mathrm{K}-12$ curriculum by the Common Core State Standards. One demand was to make mathematical modeling part of the K-12 curriculum; yet most teachers are not exposed to mathematical modeling in their preparation or professional development.

As a mathematics educator, Cynthia was interested in how mathematical modelers negotiate specific problems and what prompts the decisions they make. As a mathematician whose research involves mathematical modeling, Ricardo was curious about how mathematical modeling should be integrated in $\mathrm{K}-12$ and how teachers develop competency on a topic. In follow-up conversations we began to see that we brought incomplete but complementary knowledge of a topic that we both considered important.

\section{We brought incomplete but complementary knowledge of a topic.}

We focused on the specific questions: In what ways can prospective teachers build competency in mathematical modeling? Could carefully designed modeling modules inserted into various courses of a teacher preparation program be effective? These served as motivation to look into what was known on the topic and how we could design a research project that would provide insight. We have conducted several research projects with undergraduate mathematics majors preparing to become teachers in developing mathematical modeling competency with an added layer for teaching mathematical modeling. Our initial project (Anhalt \& Cortez 2016) was to design and implement a module of about six 75-minute class periods on the mathematical modeling process that included several modeling tasks given as contextual situations without suggesting predetermined models. We implemented the module in a pedagogy course whose students had no previous experience with mathematical modeling. The study was on a small scale but nevertheless encouraging. By the end, all of the prospective teachers had an accurate understanding of mathematical modeling as distinct from other types of "modeling" done by teachers (such as modeling an algorithmic procedure or using manipulatives as models). Furthermore, half of the prospective teachers showed an improved ability to articulate clearly that modeling is more than problem solving, involving assumptions and validation.

Another study (Anhalt, Cortez, \& Been Bennett, 2018) focused on the particular competency of making appropriate assumptions to construct a model. We designed problems that required multiple assumptions and analyzed students' work and their reflections on their work to determine when during the modeling process assumptions were made. We expected to find that assumptions were made mostly before the model was constructed; however, the analysis revealed that students continued to make assumptions through the formulation and solution phases of their modeling process. It also became clear that some assumptions were made to simplify the situation context while others were made to simplify the mathematical model. Figure 1 shows the modeling process that the students described, and it illustrates the results of our study using color-coded curves. These results help us understand the thought process carried out by the students engaged in mathematical modeling.

\section{Initiating Collaborative Work}

Initial ideas for collaborative work may stem from reaching out to colleagues; reading articles in mathematics education journals such as Mathematics Teaching and Learning, Journal of Research in Mathematics Education, or Journal of Mathematics Teacher Education; or attending targeted conferences and workshops. One specific opportunity for mathematicians to get introduced to the mathematics education research community is the series

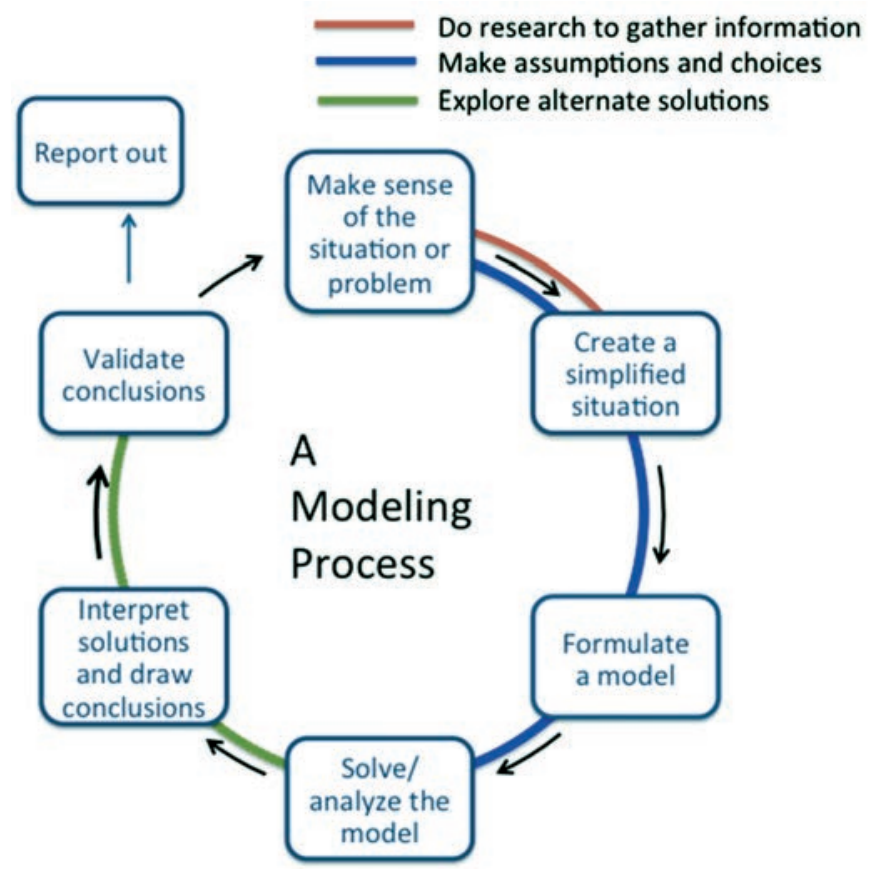

Figure 1. Schematic of the progressive modeling cycle experienced by prospective teachers, Anhalt, Cortez, \& Been Bennett, 2018.

of annual workshops, Critical Issues In Mathematics Education (CIME), that takes place at the Mathematical Sciences Research Institute (Figure 2). The purpose of these workshops is to engage mathematicians, mathematics education researchers, and $\mathrm{K}-12$ teachers in learning about research and ongoing projects across the nation. Through presentations, breakout sessions, and discussions, partic- 

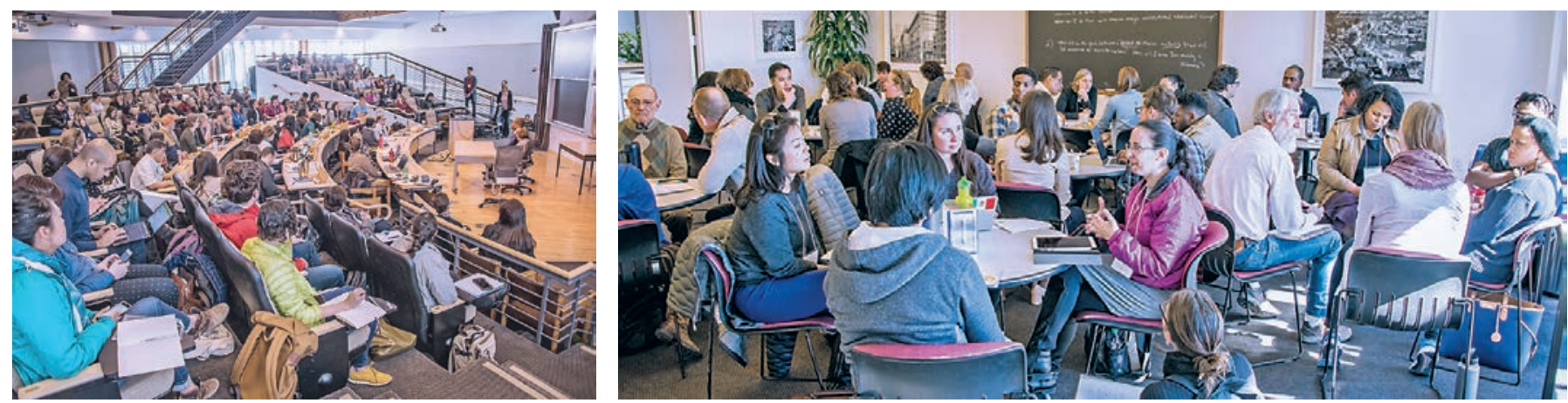

Figure 2. Meetings such as this $2018 \mathrm{CIME}$ Workshop at MSRI provide opportunities for mathematicians to get introduced to the mathematics education research community.

ipants begin to see where contributions can be made and how to leverage expertise to resolve issues in mathematics education. The workshops provide opportunities for participants to learn about development efforts that can enhance their own work related to course development, research, teaching, and assessment in K-16 education. Many research ideas are offered during the workshops, and it is up to the individuals to further develop newly established connections into collaborations.

The last two CIME workshops have focused on ways of transforming the mathematics education system to remove inequities that result in inadequate mathematical preparation of a significant proportion of students, most of them from minority populations. The theme of the upcoming 2019 workshop is mathematical modeling in K-16 and will include discussions on how to effectively teach and learn modeling, the importance of context in modeling tasks, and the level of preparation and role of mathematicians, teacher educators, and teachers as partners in this endeavor.

Other meetings that have a growing strand in mathematics education include the Joint Mathematics Meetings, the MAA MathFest, and the biennial conference of the SIAM Applied Mathematics Education activity group, ${ }^{2}$ which encourages faculty and graduate students in mathematics and mathematics education to become engaged in collaborative efforts.

Other useful resources include MAA reports on college-level programs aimed at mathematics departments to help adapt their undergraduate curricula to the widening mathematics landscape. The Curriculum Guide to Majors report, for instance, offers recommendations on content and cognitive matters and includes issues of pedagogy, access, technology, articulation, placement, and diversity. The recommendations can be considered a seed for research projects.

These professional settings provide opportunities for collegial conversations in which mathematicians can learn about mathematics education research methodology, and mathematics educators can broaden their mathematical perspectives. Mathematics education research can be enhanced through a community that involves research mathematicians who are willing to "bring valuable math- ematical knowledge, perspectives, and resources to the work of mathematics education" (Bass 2005, p. 430).

\section{References}

AnHalt, C., Cortez, R. \& BeEn BennetT, A. (2018). The Emergence of Mathematical Modeling Competencies: An Investigation of Prospective Secondary Mathematics Teachers, Mathematical Thinking and Learning, Journal of Mathematics Teacher Education 20(3) 1-20. DOI 10.1080/10986065.2018.1474532

ANHALT, C. \& CORTEZ, R. (2016). Developing understanding of mathematical modeling in secondary teacher preparation, J. Math. Teach. Educ. 19 (December 2016), 523-545. DOI 10.1007/s10857-015-9309-8. https://1ink.springer.com/ article/10.1007/s10857-015-9309-8?wt_mc=alerts. TOCjourna7s.

BASS, H. (2005). Mathematics, mathematicians, and mathematics education. Bull. Amer. Math. Soc. 42, 417-430.

Mathematical Association of America (MAA) Curriculum Guide to Majors, https://www.maa.org/programs-and-communities / curricu1um\%20resources/committee-on-the -undergraduate-program-in-mathematics

Critical Issues in Mathematics Education (CIME) Workshops at the Mathematical Sciences Research Institute (MSRI), (https:// www.msri.org/web/msri/education/for-k-12-educators /critical-issues).

\section{Image Credits}

Figure 1 Cynthia Anhalt and Ricardo Cortez (2018), The Emergence of Mathematical Modeling Competencies: An Investigation of Prospective Secondary Mathematics Teachers, Mathematical Thinking and Learning, reprinted by permission of Taylor \& Francis Ltd, www. tandfon1 ine. com.

Figure 2 courtesy of David Eisenbud.

Photo of Ricardo Cortez courtesy of Kathleen Kozar.

Photo of Cynthia O. Anhalt courtesy of Bryan McAdams.

2https://www.siam.org/activity/ed. 


\section{COMMUNICATION}

\section{ABOUT THE AUTHORS}

Ricardo Cortez's research is in computational methods for biological fluid dynamics and in mathematical modeling. is in secondary mathematics teacher education with emphasis in mathematical modeling and issues of equity.

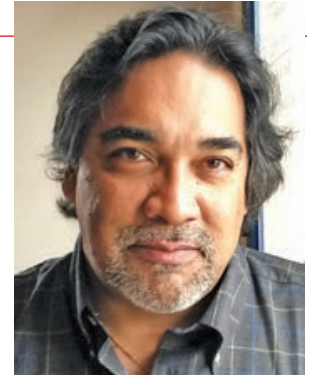

Ricardo Cortez

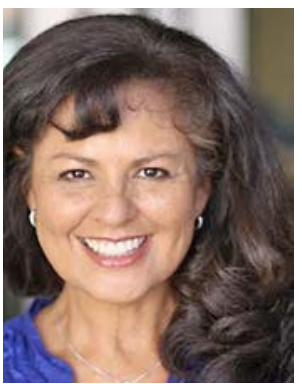

Cynthia O. Anhalt

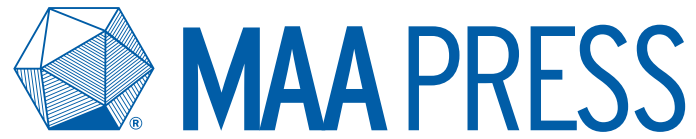

An Imprint

of the

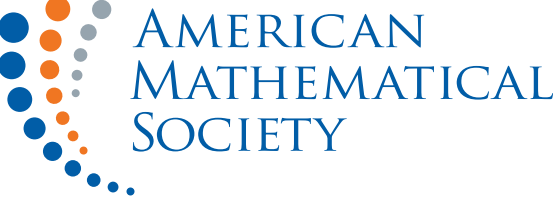

The high-quality mathematics titles and textbooks of the MAA Press are now published as an imprint of the AMS Book Program.

\section{Learn more at bookstore.ams.org}

\section{Member discounts for} MAA \& AMS members

- $25 \%$ off the list price of MAA Press titles for both MAA \& AMS members

- $20 \%$ off the list price of most other AMS titles for AMS members

- $10 \%$ off the list price of most other AMS titles for MAA members

\section{Are you interested in} AMS membership?

Visit www.ams.org /membership to learn more.

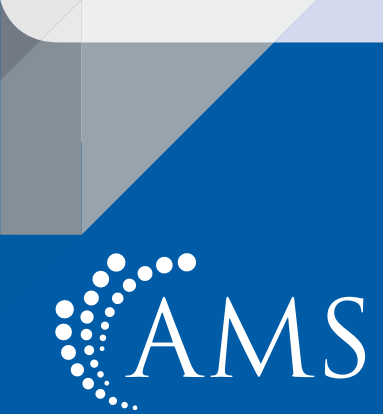

AMERICAN MATHEMATICAL SOCIETY 